\title{
Study on Pricing Model of Air Freight Based on Revenue Management
}

\author{
Xiangfei Fu¹, Yongmei Cui ${ }^{1 *}$, Suxiu Li², Peng Liang ${ }^{1}$ \\ 1 School of Economics and Management, \\ Beijing Jiaotong University, \\ Beijing 100044, China \\ ${ }^{2}$ State Grid Energy Research Institute, \\ Beijing 102209, China \\ * Corresponding author, e-mail: ymcuibjtu@163.com
}

Received: 18 October 2018, Accepted: 22 January 2019, Published online: 14 June 2019

\begin{abstract}
At present, the air freight rate does not match with the current competitive environment, and the revenue level of air freight is not ideal. How to improve the level of income management and balance the relationship between quantity and price has become an urgent problem for China's air freight. In this context, this paper constructs an air freight pricing model based on revenue management. We review the application models of the air freight, and select the parameters for pricing model. Then the pricing model is constructed based on the revenue management and the status quo of China's air freight industry. Finally, the model is tested by simulation analysis. This paper aims to provide a scientific and reasonable decision-making reference for air freight pricing through the improvement of pricing model.
\end{abstract}

\section{Keywords}

air freight, revenue management, pricing model, simulation analysis

\section{Introduction}

Since the reform and opening up, China's air freight has made considerable progress, starting from the mode of "light goods and heavy passengers" to the direction of "combining passengers and goods". However, China's air freight enterprises are facing increasingly fierce competition from foreign express delivery giants such as UPS and FedEx. At present, China's air freight enterprise management faces many problems. First, the air freight rate does not match with the current competitive environment. Domestic air freight rates, mainly taking weight and distance as benchmark, are stipulated on national unified regulation. However, price discrimination is an important mean as for revenue management in the marketing process. The current freight rate strategy lacks of flexibility in matching with the value of the goods and specific strategy for value estimation. Second, the revenue level of air freight is not ideal. In terms of cargo carrying capacity, the cargos on China's civil aviation are mostly low value goods without added value, while foreign airlines mostly rely on goods with high added value.
At present, there are few studies on the management of air freight revenue management, and the comprehensive analysis of the influencing factors and mechanism of air freight pricing are insufficient. Based on the current research results, this paper analyzes the main factors affecting the pricing of air freight in view of the operational characteristics of air cargo transport industry and the actual operation of the major cargo airlines in China. This paper constructs a model for air cargo price and highlights the practicality of freight revenue management.

Rest of the paper is organized as follows. Literature review is presented in Section 2. Section 3 establishes a pricing model of air freight based on revenue management. Section 4 gives the simulation analysis results of the air freight model. Section 5 concludes the study.

\section{Literature review}

Revenue management is a kind of new business management technology that maximizes revenue, which determines the best sales or service price by establishing real-time 
prediction model and analyzing the demand behavior based on market segmentation such that the profit of the enterprise is maximized. The core idea of revenue management is the price subdivision, to execute different price criteria to customers according to the different demand characteristics and price elasticity of customers, so as to achieve maximum economic benefits. Weatherford and Bodily (1992) proposed the concept of "Perishable-Asset Revenue Management", which believes that the value of perishable goods exists within a certain period of time, and put forward fourteen criteria for identifying perishable revenue management. Other scholars believe that revenue management is not only an important management tool to improve corporate income, but also an advanced technical means (Donaghy et al., 1995; Yang and Du, 2016). According to Westering (1994) from the perspective of enterprises, revenue management should be based on demand forecasting. In the peak season, the price should be maximized to increase the profit, while in the off-season, the profit should be increased by increasing the sales volume. Other scholars analyze the impact of market demand, dynamic pricing, inventory control and other factors on the income from a system perspective, emphasizing that revenue management is an important business strategy of the enterprise, and that the highest goal of revenue management is to maximize the overall revenue (Billings et al., 2003).

There are also many studies on the application of revenue management to air freight. Littlewood (2005) proposed marginal seat revenue rules and applied to single-segment, two-class air ticketing and space allocation. Based on revenue management, Rothstein (1971) put forward a decision-making model for overbooking. Belobaba $(1987 ; 1989)$ proposed a probability model and established an EMSR (Expected Marginal Seat Revenue) rules. In air cargo research, Kasilingam (1997) explored the characteristics and complexity of air freight revenue management by comparing the difference between air passenger and air cargo, and considered that the main strategy of air cargo revenue management is stock control. Other scholar argued that freight revenue management involves medium-term planning and short-term planning (Billings et al., 2003), the goal of freight revenue management is to maximize revenue and must consider revenue, variable costs (Slager and Kapteijns, 2004) and customer demand (Du et al., 2017; Han et al., 2010). Feng and Xiao (2000a; 2000b) studied the multi-stage and multi-price optimal pricing strategy to prove the unity of the price strategy and the maximum number of times the price was changed.

\section{Establishment of pricing model of air freight based on revenue management}

3.1 Parameter determination of pricing model of air freight 3.1.1 Selection principle of model parameters

The particularity of air freight products is that they cannot be stored, so this paper mainly studies the short term pricing of air freight. However, a key point in the revenue management is that the market demand is taken as the standard rather than the cost when setting the prices, so the revenue management personnel temporarily do not need to pay attention to the cost, while the demand for air transport industry is constantly changing. As the enterprises without obvious monopoly, it is not enough to determine one demand curve only for transportation enterprises with the decrease of their position. The pricing models of air freight in the past were mostly developed only according to the nature of principle, concealing the optimal price, such that the optimal price could not be confirmed. The pricing model in this paper is mainly based on the assumption that the air freight enterprise originally reserves the price subject to a certain distribution law to determine the best price according to the slot of air freight.

\subsubsection{Selection and determination of model parameters}

Air freight is booming. Because airlines have monopoly power in the provision of routes, they can rise and fall the prices to influence demand changes. Based on this, the construction of freight pricing model in this paper mainly reflects the reasonable prediction on demands by enterprises and the demand influenced by adjusting price. The variables involved in the model are as follows:

$n$ : the number of space of an air freight enterprise to accommodate maximum goods. Here assume $1 \mathrm{~m}^{3}$ as a base unit, $n$ is the base unit of $n$,

$t$ : sales time, that is, the time required to sell the space completely after adjusting the price to change the market demand by enterprise. Here assume that the residual value after sale is 0 , that is, there is no flight with void space. $P$ : sale price of unit space of enterprise,

$\mathfrak{R}^{*} \cup\left\{P_{\infty}\right\}$ : set of sale price of enterprise, that is, the set of price changes set by enterprise,

$a$ : arrival rate of potential shipper in the industry market,

$\lambda$ : potential shipper purchasing rate in the industry market (mainly obeying the Poisson distribution),

$f(p)$ : probability density function of reservation price distribution by potential shipper in the industry market (every potential shipper in the market has their own reservation price for the space they need to order), 
$F(p)$ : cumulative distribution function of reservation price distribution by potential shipper in the industry market, $1-F(p)$ : purchase ratio of a specific potential shipper in the industry market,

$N(t)$ : random demand of slot at time of $t$ in industry,

$J(\lambda, t, n)$ : expected revenue under demand strength of $\lambda$ (when $\lambda$ is the best strategy, which is corresponded to $P$ one to one, then the best price can be calculated with inverse function).

\section{2 Establishment of pricing model of air freight based on revenue management}

\subsubsection{Establishment of pricing model of air freight based on revenue management}

The reservation price distribution is designated as Weibull distribution $\left(F(p)=1-e^{-\alpha p \beta}\right)$ or exponential distribution $\left(F(p)=1-e^{-\alpha p}\right)$ in model for the convenience of calculation (The two different distributions will be analyzed in follow, respectively.)

In the whole freight market, the purchase rate of specific potential shipper is influenced by many factors, which are mainly three factors, such as the arrival rate of specific potential shipper $a$, the ratio of the specific shipper to purchase the freight space $1-F(p)$, and the distribution of reservation price $F(p)$, so $\lambda$ can also be expressed as $a(1-F(p))$.

The freight enterprises are required to develop a pricing strategy based on the maximization of income for the current situation and market dynamics before the sales start.

The stability of the enterprise cost structure determines the formation of profit maximization when the enterprise realizes the optimal income. Therefore, it is assumed in the model that when the departure date is set up, the operation cost of airlines will not be greatly influenced by the changes in sales volume during the sales process. Here, this paper regards such cost as the sunk cost of enterprise, and on this basis, the research of this model can mainly aim at achieving the profit maximum.

According to the hypothesis of the Poisson distribution of the index system, the probability distribution of the random demand of freight space $N(t)$ is as follows:

$P(N(t)=j)=\frac{\lambda t^{j} e^{-\lambda t}}{j !} \quad j=0,1,2, \ldots, \infty$, then the optimal revenue equation can be obtained as follow:

$$
\begin{aligned}
J(\lambda, t, n) & ={ }_{p \in P}^{p} E \min (n, N(t)) \\
& =\sum_{j=0}^{n} p j P(N(t)=j)+p n\left(1-\sum_{j=0}^{n} P(N(t)=j)\right) \\
& =\sum_{j=0}^{n} p j \frac{\lambda t^{j} e^{-\lambda t}}{j !}+p n\left(1-\sum_{j=0}^{n} \frac{\lambda t^{j} e^{-\lambda t}}{j !}\right) .
\end{aligned}
$$

In Eq. (1), the front $\sum_{j=0}^{n} p j \frac{\lambda t^{j} e^{-\lambda t}}{j !}$ represents the expected revenue when the random demand is less than or equal to $n$, and the subsequent $p n\left(1-\sum_{j=0}^{n} \frac{\lambda t^{j} e^{-\lambda t}}{j !}\right)$ means the expected revenue when the random demand is greater than $n$.

Bring $\sum_{j=0}^{n} p j \frac{\lambda t^{\prime} e^{-\lambda t}}{j !}=1-\sum_{j=n+1}^{\infty} p j \frac{\lambda t^{\prime} e^{-\lambda t}}{j !}=1-\int_{0}^{t} \frac{\lambda^{n+1}}{\Gamma(n+1)} x^{n} e^{-\lambda x} d x$ into Eq. (1), the equation can be simplified as follow:

$J(\lambda, t, n)=p \lambda t[1-G(n, \lambda)]+p n G(n+1, \lambda)$.

Where, $G(n, \lambda)=\int_{0}^{1} \frac{\lambda^{n}}{\Gamma(n)} x^{n-1} e^{-\lambda x} d x$ and $\Gamma(n)=\int_{0}^{+\infty} x^{n-1} e^{-x} d x$.

Define $G(n, \lambda)$ as the cumulative function of Gamma distribution, hence: $G(n+1, \lambda)<G(n, \lambda)$.

Assume $V(t, n)=\underset{p \in P}{\text { sup }} J(\lambda, t, n)$, which represents the optimal expected revenue upon given $t$ and $n$.

When $\frac{\vartheta J(\lambda, t, n)}{\vartheta \lambda}=0$, the optimal expected revenue $V(t, n)$ can be obtained as follow:

$$
\begin{aligned}
& \frac{\vartheta J(\lambda, t, n)}{\vartheta \lambda}=(p \lambda t)^{\prime}[1-G(n, \lambda)]+p \lambda t\left(-\frac{t}{\lambda} g(n, \lambda)\right) \\
& +\frac{d p}{d \lambda} n G(n+1, \lambda)+p n \frac{t}{\lambda} g(n+1, \lambda)=0 .
\end{aligned}
$$

Where $g(n, \lambda)=\frac{\lambda^{n}}{\Gamma(n)} t^{n-1} e^{-\lambda t}$. The following equation can be obtained as per the nature of probability density function of Gamma distribution: $\frac{\vartheta G(n, \lambda)}{\vartheta \lambda}=\frac{t}{\lambda} g(n, \lambda)$ and $g(n+1, \lambda)=\frac{\lambda t}{n} g(n, \lambda)$. The following equation can be obtained after substituting above equations into the Eq. (3):

$(p \lambda t)^{\prime}[1-G(n, \lambda)]+\frac{d p}{d \lambda} n G(n+1, \lambda)=0$.

First, reservation price expressed by Weibull distribution

$F(p)=1-e^{-\alpha p \beta}, \lambda=a e^{-\alpha p \beta}, \quad p=\left(-\frac{1}{\alpha} \ln \frac{\lambda}{a}\right)^{\frac{1}{\beta}}$. Equation (5) The following equation can be obtained after substituting above equations into the Eq. (4):

$$
\left(-\frac{\lambda t}{\alpha \beta \lambda p^{\beta-1}}+p t\right)(1-G(n, \lambda))+\left(-\frac{1}{\alpha \beta \lambda p^{\beta-1}}\right) n G(n+1, \lambda)=0 .
$$

The following can be obtained by simplifying the Eq. (5):

$\frac{G(n+1, \lambda)}{1-G(n, \lambda)}+\frac{\lambda t}{n}\left(1+\beta \ln \frac{\lambda}{a}\right)=0$ 
The calculate $\lambda^{*}$ satisfying the Eq. (6), that is the stagnation point of $J(\lambda, t, n)$, which means $J(\lambda, t, n)$ can reach the only maximum value at $\lambda^{*}$.

Second, reservation price expressed by exponential distribution

$F(p)=1-e^{-\alpha p}$ and $\lambda=a e^{-\alpha p}$, which can be considered as the special Weibull distribution of $\beta=1$. The Eq. (7) can be obtained by substituting $\beta=1$ into the Eq. (6), in which $\lambda^{*}$ satisfying the formula is the stagnation point of, namely optimal point.

$\frac{G(n+1, \lambda)}{1-G(n, \lambda)}+\frac{\lambda t}{n}\left(1+\ln \frac{\lambda}{a}\right)=0$.

At this moment, the optimal price is $p^{*}=-\frac{1}{\alpha} \ln \frac{\lambda^{*}}{a}$, the maximum value of optimal demand strength ${ }^{a} \lambda^{*}$ is $\lambda_{\max }^{*}=a e^{-1}$ and the minimum value of optimal price $p^{*}$ is $p_{\min }^{*}=\frac{1}{\alpha}$.

\subsubsection{Analysis of pricing model of air freight}

The nature of the optimal price obtained by numerical simulation is not very ideal and complete in general literature. Analyzing the nature of the optimal price by applying the analytic method, the following 3 theorems can be accessed.

Theorem 3-1: $t^{*}$ is the decreasing function of arrival rate of potential shipper $a$, which decreases with increase of $a$; the optimal price $p^{*}$ is the increasing function of $a$, which may accordingly fluctuate with increase of $a$.

The purchase rate of shipper and the price will rise with the increase of arrival rate of potential shipper $a$. Therefore, increasing the arrival rate of potential shipper by marketing is a feasible way that effectively improves the revenue, which can be considered as the long-term aim in business operations in future.

Theorem 3-2: the optimal price is an increasing function of sales time, which will increase with the increase of sales time. When the sales time is short, the optimal price will keep approximately the minimum value, and the expected revenue will change linearly with the sales time.

In the past, the way to change price as per time and demand way was barely prior to presale of freight space in China's air freight market, so it was hard to be flexible and unable to adapt to the market changes effectively. Nowadays, the presale of freight space not only has realized the flexibility of both sides in transaction, but also gave the freight company certain opportunity to adapt to the market and change the pricing, so as to maximize its own revenue. The same pre-sale increases the sales time of the freight industry, provides a time guarantee for reasonable pricing and decision making, reduces its own market risks and protects its legitimate interests.

Theorem 3-3: when $\alpha \beta \leq 1$, the optimal price $p^{*}$ is the decreasing function of $\beta$; when $\alpha \beta>1$, the impact on $p^{*}$ by $\beta$ is related to the value of other parameters. $t^{*}$ is independent of $a$; the optimal price $p^{*}$ is the decreasing function of $a ; t^{*}$ is the decreasing function of $\beta$.

\section{Simulation analysis of pricing model of air freight based on revenue management}

\subsection{Sample selection and variable description}

The optimal pricing Eq. (4) described in above section is tested by simulation analysis method through the MATLAB 7.1 mathematical tool. Combined with Eqs. (6) and (7) acquired in Section 3.2.1, the specific operations can be conducted to get the optimal pricing $p^{*}$, optimal demand intensity $\lambda^{*}$ and optimal sales cycle $t^{*}$ of air freight enterprises under given variables. The effectiveness of the result is analyzed combining with the actual conditions in the air freight industry, and the validity of the model is verified at the same time.

The sample of given parameter shall be determined based on above analysis. The sample selection of this paper is mainly from the route of domestic ordinary transport companies, and the number of freight space can also be obtained based on the valuation.

The specific variable values of the simulation analysis are as follows:

$n$ : about 800 units (number of available freight space of cargo aircraft operated on one route for a domestic airline),

$t: 35$ days (original sales time, sales cycle of an ordinary air freight company),

a: 70 (shipper arrival rate, estimated by historical data), $\alpha: 1.5$ (common exponential distribution coefficient),

$F(p)=1-e^{-1.5 p}, \lambda=\alpha[1-F(p)]$ (the unit of $p$ and $\lambda$ are ten thousand yuan $/ \mathrm{m}^{3}$ and $\mathrm{m}^{3} /$ day respectively).

Through the above parameters, the optimal price is calculated after substituting Eqs. (6) and (7), to verify the applicability of the model.

Based on verifying the applicability and effectiveness of the model, this section also uses MATLAB 7.1 mathematical tool and data substitution to draw relationship graph by changing the variables. In such case, the relationship among arrival rate of potential shipper, optimal sales cycle and optimal pricing can be researched by changing the arrival rate of potential shipper. The mutual change relationship among the optimal price and parameters 
$\alpha$ and $\beta$ also can be researched by changing the parameters $\alpha$ and $\beta$ to alter the price demand elasticity for freight space. The three theorems reflected in the model analysis mentioned above are verified by the relationship graph.

The following will be divided into three cases to analyze and verify on account of this situation.

First, the variable parameter $c$ is set as $a=65, a=85$, and $a=95$ respectively in the case of the rest variables fixed ( $n$ : about 800 units; $t: 35$ days; $\alpha: 1.5$ ). The relationship graph is used to research the influence of the arrival rate of potential shipper and the optimal pricing and the expected revenue and explore the inner relationship.

Second, the $\alpha$ is set as $\alpha=1.6, \alpha=1.8$, and $\alpha=2.0$ respectively in the case of the rest variables fixed ( $n$ : about 800 units; $t: 35$ days; $a: 70)$. The relationship graph is used to research the impact of price demand elasticity coefficient $\alpha$ on optimal pricing and the expected revenue and analyze the mutual influence relationship among them so as to provide basis for development of aircraft industry.

Third, the analysis in carried out by the following two cases under rest variables unchanged ( $n$ : about 800 units; $t: 35$ days; $a: 70 ; \alpha=1.6$ ), that is, three values are taken for $\beta$ when $\alpha \beta \leq 1: \beta=0.55, \beta=0.6$ and $\beta=0.65$. Three values are taken for $\beta$, when $\alpha \beta>1$ : $\beta=1.2, \beta=1.5$ and $\beta=1.8$. The relationship graph is used to research the impact of price demand elasticity coefficient $\beta$ on optimal pricing and the expected revenue and analyze the mutual influence relationship among them.

\subsection{Data simulation test and result analysis}

\subsubsection{Data simulation test}

The specific calculation process of Eq. (7) in Section 3.2.1 by virtue of the given parameters:

Before the whole sale process starts, the air freight enterprises need to determine their own optimal price to achieve the optimal expected revenue according to the known market conditions.

The given parameters are substituted into Eq. (7), and the following equation can be acquired:

$$
\left.\frac{G(801, \lambda) \times 800}{(1-G(800, \lambda)) \times 35}+\lambda+\lambda \ln \frac{\lambda}{70}\right)=0
$$

which is substituted into MATLAB 7.1 for operation

The following results are calculated according to the calculation:

$\lambda^{*}=25.75 \mathrm{~m}^{3} /$ day, that is, the optimal demand strength is $25.75 \mathrm{~m}^{3} /$ day at this time.w

The optimal price is substituted into Eq. (4) in Section 3.2.1 to calculate the optimal price $p^{*}=6667$ yuan $/ \mathrm{m}^{3}$.
After the above operation, the optimal expected revenue $V(35,800)=6,008,698$ yuan can be calculated by Eq. (1) in 3.2.1.

$t^{*} \approx 23$ days are calculated by inverse function.

The optimal sales cycle is shorter than the original sales cycle by calculation. In such case, the air freight industry is required to adjust the supply and cycle to shorten the sales cycle in order to ensure they can be close to the maximum benefits. The sales price can be adjusted appropriately to close to the optimal price based on the adjustment of cycle, and vice versa.

\subsubsection{Analysis of test results}

Next, the numerical simulation is adopted to study the optimal sales cycle and the relationship between it and optimal pricing by changing the arrival rate of potential shipper. The price demand elasticity of freight space is altered by changing parameters $\alpha$ and $\beta$, to study the mutual variation relationship among optimal price and the parameters $\alpha$ and $\beta$.

(1) Relationship between arrival rate of potential shipper and optimal price

Under the condition that the given parameter $n=800$ and $F(p)=1-e^{-1.5 p}$ are unchanged, the relationship between the arrival rate of potential shipper and the optimal price is observed by changing the value of arrival rate of potential shipper $a$. Based on this, three sets of data are set up in this paper: $a=65, a=85$ and $a=95$. The relationship graph is obtained by data output, as shown in Fig. 1 and Fig. 2.

It can be found from Figs. 1 and 2 that when the arrival rate of enterprises' potential shipper $a$ rises, the transportation demand of shipper also correspondingly increases, but the optimal time $t^{*}$ is shortened. At this moment, the enterprise can increase the pricing of freight space to gain the greater expected profits, which also is proved in Fig. 3.

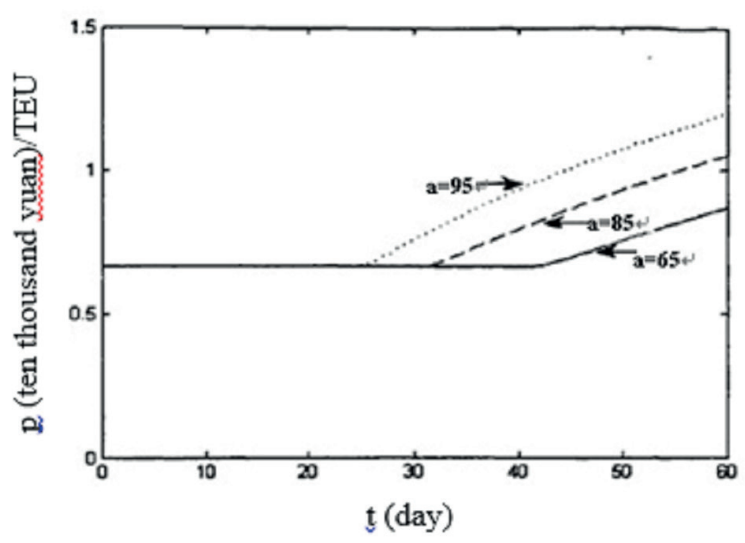

Fig. 1 Relationship between optimal price and arrival rate 


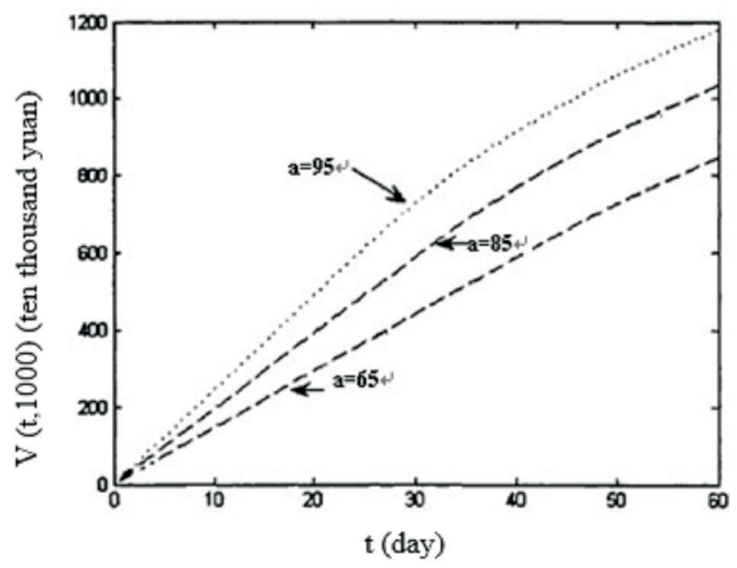

Fig. 2 Impact of arrival rate of potential shipper on expected revenue

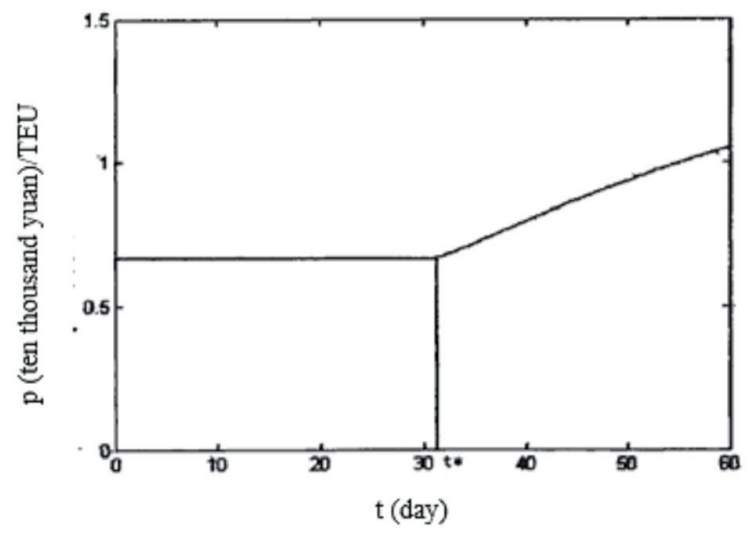

Fig. 3 Relationship between optimal price and sales time

This conclusion is in agreement with Theorem 3-1, when the enterprise estimates that the arrival rate of potential shipper increases, the transportation demand of shipper also correspondingly will rises, while the enterprise can increase the supply of their own to meet the rising market demand. Similarly, with the optimal sales time shortened, the enterprise can enhance the space price in proper to obtain higher returns.

(2) Relationship between sales time and optimal price

In case of the given parameter $n=800$ and $a=70$, the relationship diagram between the optimal price, optimal expected revenue and sales time can be developed by using MATLAB 7.1, to get the variation influence of the optimal price, optimal expected revenue and the sales time, as shown in Fig. 3 and Fig. 4.

It can be seen from Fig. 3 that in the case of $t<t^{*}$, as the air freight companies have more freight space, they will choose as far as possible to attract customers by other means, commonly by low price in most airlines (i.e. 6700 yuan $/ \mathrm{m}^{3}$ in Fig. 4) to attract customers to sell more freight space, so as to sale all the space in the fixed sales period and avoid empty space resulting in interest loss. In

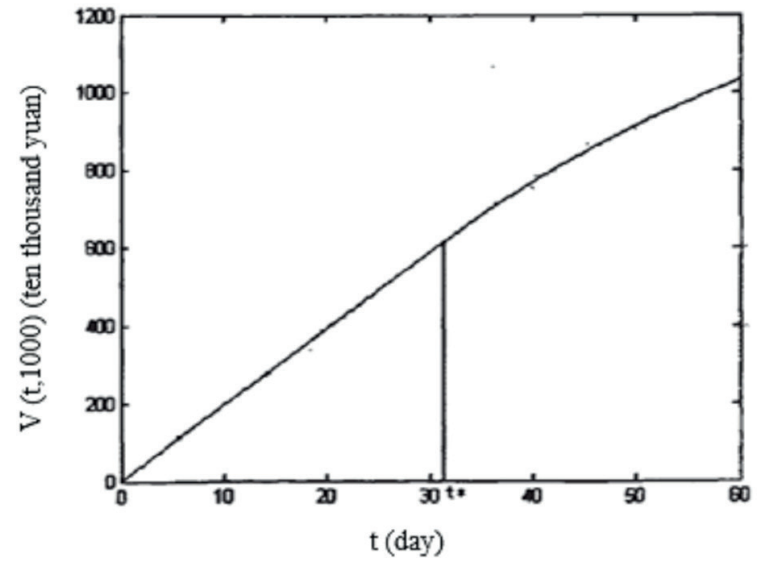

Fig. 4 Impact of sales time on optimal expected revenue

the case of $t>t^{*}$, the longer the sales cycle is, the more time air freight company will have to sell, leading to more sales opportunities. By this time, the airline can raise the price based on the original price and improve the starting point since there is no certain competition and bidding pressure, to contribute to taking discount and other measures for coping with changes, indirectly reducing the loss.

We can see from Fig. 4 that the longer the air freight company's sales time is, the higher the expected earnings of the company will be. In case of $t<t^{*}$, the increase of expected revenue with growth of sales time is very sharp. However, in case of $t>t^{*}$, the marginal expected revenue is in decline and the revenue growth rate of enterprises is gradually slow when the expected revenue of air freight enterprises increases with growth of sales time. This conclusion is in agreement with the Theorem 3-2 in the paper. The air freight enterprises should reasonably control the sales cycle within the optimal sales time obtained in the model to the greatest extent, so as to ensure that enterprises can increase profits by the most high-speed way.

(3) Relationship between parameter $\alpha$ and optimal price

Under the condition that test parameters $n=1000, a=70$ and $\beta=1$ remain unchanged, the relationship between the parameter and the optimal price through the change of. This paper sets three sets of data: $\alpha=1.6, \alpha=1.8$ and $\alpha=2.0$. The relationship graph among parameter $\alpha$, optimal price and optimal expectation is acquired by summarizing, as shown in Fig. 5 and Fig. 6.

It can be observed from Fig. 5 and Fig. 6 that the influence relationship between price and demand are gradually becoming more and more close with the increase of impact. When the shipper is more sensitive to price, the selection ability of shipper is correspondingly increased. When the air freight company reduces its pricing of space, their expected revenue reduces accordingly, and vice 


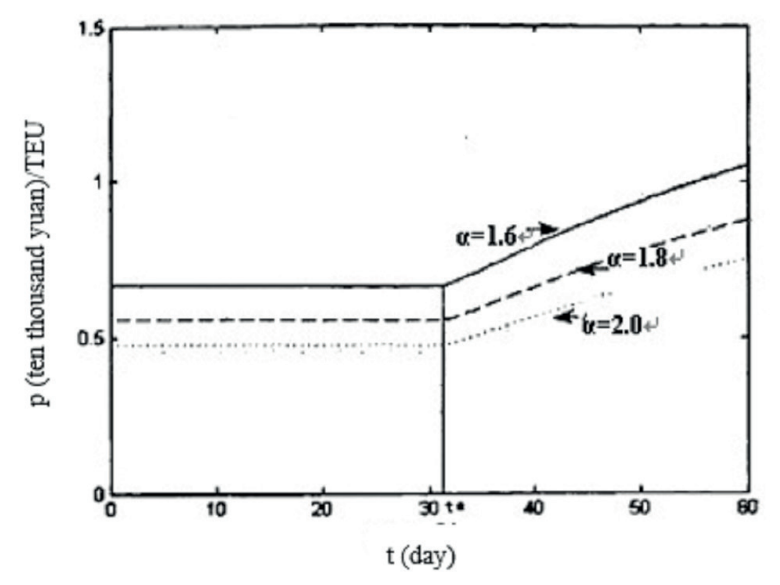

Fig. 5 Relationship between optimal price and $\alpha$

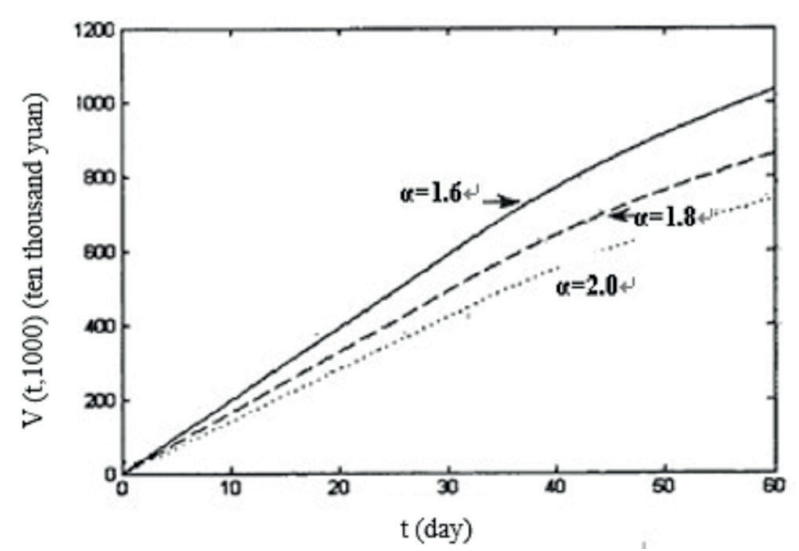

Fig. 6 Impact of $\alpha$ on optimal expected revenue

versa. From Fig. 6, it also can be known that the minimum value of the optimal price is determined by $\alpha$, but the change in the value of $\alpha$ is not able to affect the value of $t^{*}$. This conclusion is in agreement with Theorem 3-3.

(4) Relationship between parameter $\beta$ and optimal price

This discussion is conducted by the following two cases in this paper provided that the test parameters $n=800$, $a=70$, and $\alpha=1.6$ remain unchanged.

In case of $\alpha \beta \leq 1$ :

As shown in Fig. 7, when $\beta$ is relatively small $(\alpha \beta \leq 1)$, that is, the price demand elasticity of freight space is relatively small, the air freight company can maintain its pricing at a relatively high level in a long period, which makes itself to maintain a lasting high income.

Three values are taken for $\beta$ when $\alpha \beta>1: \beta=1.2, \beta=1.5$ and $\beta=1.8$. Fig. 8 represents the relationship between optimal price and $\beta$.

It can be known from Fig. 8 that the price demand elasticity of freight space, when $\beta$ is larger $(\alpha \beta>1)$, $\mathrm{s}$ relatively large, and the impact of price fluctuation on demand will be relatively large, which means that the

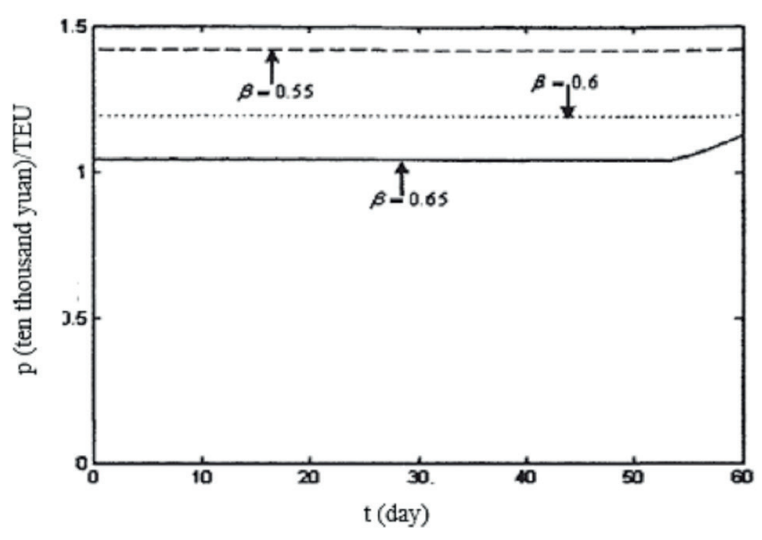

Fig. 7 Relationship between optimal price and $\beta$ when $\alpha \beta \leq 1$

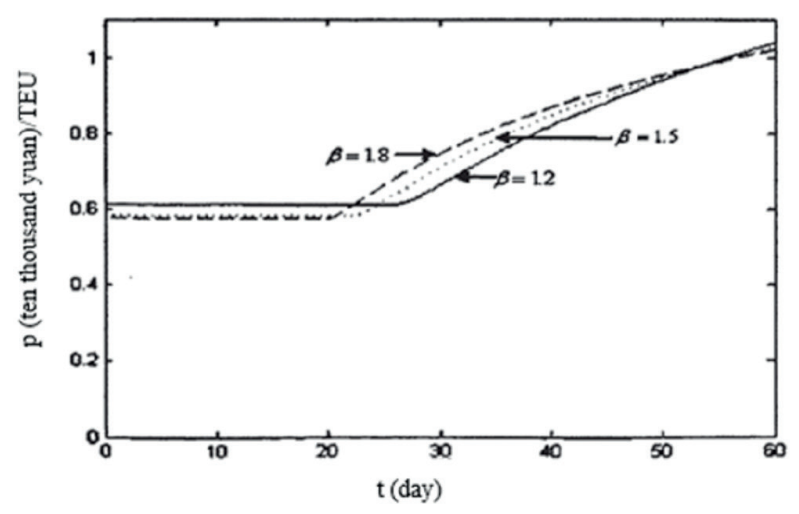

Fig. 8 Relationship between optimal price $\beta$ and when $\alpha \beta>1$

shipper is sensitive to price changes, so the selection of booking space for shipper will be greatly changed due to other external factors. At this time, the optimal price of freight space $p^{*}$ is not monotonic to $\beta$.

This conclusion is consistent with Theorem 3-3.

This section verifies the applicability and reliability of pricing model built by us for air freight companies by mathematical tools and simulation analysis and confirms the existence value of the model, to provide certain guidance for air freight company forecasting market, making the optimal price, deciding the sales cycle and conducting revenue budget.

At the same time, combined with the relationship graph and variable analysis with parameter variation, the conclusions drawn by law of mathematics and variation way in this section are consistent with the three theorems obtained in the process of model analysis, to further prove the regularity of the model. Meanwhile, combined with the reality of air freight industry, this series of relationship rules are effectively utilized to put forward the variable control of air freight industry in model application and the problem about how to better use the model in reality, so as to enable enterprises to receive greater profits. 


\section{Conclusions}

This paper takes the air cargo enterprise as the research object, and builds the mathematical model from the perspective of the air freight pricing model. From the normative and empirical aspects, we study the importance of the pricing model of the air cargo industry.

The main conclusions in this paper are as follows. First, China's air freight industry should make clear the goal of revenue management in consideration of pricing, that is, to maximize revenue.

Second, according to the relevant theory of revenue management and the research achievement about pricing model of air freight at current stage, it can be found that the pricing is mainly affected by the time, market demand, arrival rate of potential shippers and purchase rate, the reservation price distribution by shipper and many other factors. Hence, various factors should be considered when developing the model.

Third, combined with the above factors, a pricing model of air freight based on revenue management is established, including the index system and the application principle of the model, as well as the verification of theorem in the

\section{References}

Belobaba, P. P. (1987) "Survey Paper - Airline yield management an overview of seat inventory control", Transportation Science, 21(2), pp. 63-73. https://doi.org/10.1287/trsc.21.2.63

Belobaba, P. P. (1989) "OR practice - application of a probabilistic decision model to airline seat inventory control", Operations Research, 37(2), pp. 183-197.

https://doi.org/10.1287/opre.37.2.183

Billings, J. S., Diener, A. G., Yuen, B. B. (2003) "Cargo revenue optimisation", Journal of Revenue and Pricing Management, 2(1), pp. 69-79. https://oi.org/10.1057/palgrave.rpm.5170050

Donaghy, K., McMahon, U., McDowell, D. (1995) "Yield management: an overview", International Journal of Hospitality Management, 14(2), pp. 139-150. https://doi.org/10.1016/0278-4319(95)00013-3

Du, J., Qiao, F., Yu, L., Gao, L. (2017) "Planning of Campus Area Nighttime Public Transportation System Based on GIS and Operation Research", presented at Transportation Research Board 96th Annual Meeting, Washington, DC, USA, Jan. 8-12, 2017.

Feng, Y., Xiao, B. (2000a) "A continuous-time yield management model with multiple prices and reversible price changes", Management Science, 46(5), pp. 644-657. https://doi.org/10.1287/mnsc.46.5.644.12050

Feng, Y., Xiao, B. (2000b) "Optimal policies of yield management with multiple predetermined prices", Operations Research, 48(2), pp. 332-343. https://doi.org/10.1287/opre.48.2.332.13373

Han, D. L., Tang, L. C., Huang, H. C. (2010) "A Markov model for singleleg air cargo revenue management under a bid-price policy", European Journal of Operational Research, 200(3), pp. 800-811. https://doi.org/10.1016/j.ejor.2009.02.001 model. The validity of the model is verified by the simulation test. Finally, the feasibility of established pricing model of air freight based on revenue management is confirmed.

Forth, in this paper, the pricing-related problems of air freight are researched quantitatively based on the revenue management. Meanwhile, a series of rules in the model is obtained by the simulation analysis to determine the optimal pricing equation of air freight space (the interaction among the optimal price, sales time and parametric variables: the optimal sales cycle $t^{*}$ is the decreasing function of arrival rate of potential shipper $a$; the optimal price $p^{*}$ is the increasing function of arrival rate of potential shipper $a$; the optimal price $p^{*}$ is the decreasing function of the price elasticity coefficient of space $a ; t^{*}$ is the decreasing function of the price elasticity coefficient of space $\beta$ ).

Fifth, the optimal pricing model is established based on the multiple influencing factors combining with researches in this paper. The simulation test is conducted with MATLAB 7.1 and the conclusions drawn in model is verified, which confirms the applicability of established model and the truth of the rule obtained in the model.

Kasilingam, R. G. (1997) "Air cargo revenue management: Characteristics and complexities", European Journal of Operational Research, 96(1), pp. 36-44. https://oi.org/10.1016/0377-2217(95)00329-0

Littlewood, K. (1972) "Special Issue Papers: Forecasting and control of passenger bookings", Journal of Revenue and Pricing Management, 4(2), pp. 111-123.

https://doi.org/10.1057/palgrave.rpm.5170134

Rothstein, M. (1971) "An airline overbooking model", Transportation Science, 5(2), pp. 180-192. https://doi.org/10.1287/trsc.5.2.180

Slager, B., Kapteijns, L. (2004) "Implementation of cargo revenue management at KLM", Journal of Revenue and Pricing Management, 3(1), pp. 80-90. https://doi.org/10.1057/palgrave.rpm.5170096

Weatherford, L. R., Bodily, S. E. (1992) "A taxonomy and research overview of perishable-asset revenue management: Yield management, overbooking, and pricing", Operations Research, 40(5), pp. 831-844. https://doi.org/10.1287/opre.40.5.831

Westering, J. V. (1994) "Yield management: the case for food and beverage operations", In: Progress in tourism, recreation and hospitality management, Wiley, Chichester, United Kingdom, pp. 139-147. https://doi.org/10.1016/0261-5177(95)90067-5

Yang, H., Du, J. (2016) "Study on efficiency of supply chain based on single revenue sharing contract and double contracts combination", In: International Conference on Logistics, Informatics and Service Sciences (LISS), Sydney, NSW, pp. 1-7. https://doi.org/10.1109/LISS.2016.7854341 